\title{
Easily performed interval exercise induces to increase in skeletal muscle PGC-1 $\alpha$ gene expression
}

\author{
Hiroaki Tanaka*, Seiya Ueno, Ryo Aoyagi, Yoichi Hatamoto, Magdalena Jackowska, Keisuke Shiose and Yasuki Higaki \\ Fukuoka University Institute for Physical Activity, Fukuoka University, 8-19-1 Nanakuma Johnanku Fukuoka, Japan 814-0180
}

\begin{abstract}
Introduction: Understanding the relationship between PGC-1 $\alpha$ expression and exercise is important for developing therapeutic exercise programs focusing on the prevention of lifestyle diseases. The current study examined whether easily performed modearte intensity interval exercise can induce PGC-1 $\alpha$ gene expression Methods: Nine subjects performed cycling in one of three protocols: maximal intensity [MIE: $20 \times 1$ min with 4 min recovery], high intensity [HIE] and a moderate intensity at anaerobic threshold interval exercise [AIE]. Both HIE and AIE were adjusted to obtain the same exercise volume as MIT performed for $5 \mathrm{~min}$ including recovery time and repeated 20 times. Results: Increase in PGC-1 $\alpha$ mRNA expression was observed in all conditions. with a significant increase in plasma epinephrine. ACC phosphorylation also increased in all condition. Conclusion: These findings suggest that easily performed interval exercise at anaerobic threshold induces PGC$1 \alpha$ expression which induce aerobic training adaptation.
\end{abstract}

\section{Introduction}

Physical inactivity has resulted in a drastic increase in the prevalence of a number of chronic diseases [1]. Given its health consequences, understanding the relationship between PGC-1 $\alpha$ expression and exercise is important for developing therapeutic exercise programs focusing on the prevention of lifestyle diseases [2]. Numerous studies have shown that prolonged endurance exercise results in PGC-1a expression and improves aerobic capacity after several weeks of training [3]. Moreover, there is evidence that low volume sprint interval exercise has similar effects to traditional endurance training, eliciting similar levels of PGC-1 $\alpha$ and aerobic adaptation as typical endurance exercise training [4] [5]. Moreover, it has been shown that practical aerobic interval exercise $(10 \times 1 \mathrm{~min}$ at $85-95 \%$ heart rate reserve interspersed with 1 min recovery) increases markers of skeletal muscle mitochondrial content and glucose transport capacity in sedentary middle-aged adults [6].

Accessibility and ease of completion are major considerations in creating therapeutic exercise programs for the general public. As such, short periods of higher-intensity interval exercise that have the same effect on PGC-1 $\alpha$ expression as long durations of continuous exercise presents an attractive prospect. However, for participants in exercise therapy programs, who often suffer from illnesses or obesity and have low levels of fitness [e.g., sedentary middle-aged or elderly people], even the $85-95 \% \mathrm{HR}$ exercise is hard to practice in the longer term. In addition, short bursts of exercise are ineffective in weight loss because of the relatively small energy expenditure involved.

We already showed that even the moderate intensity exercise for 1hour duration could induce PGC-1a expression [7]. We hypothesis that the easily performed interval exercise with short duration for several min which might easily performed even in elderly patients could induce PGC-1 1 expression.

The current study sought was to verify whether moderate intensity exercise at anaerobic threshold performed in intervals (AIE) leads to a
PGC-1 $\alpha$ mRNA expression increase similar to that observed in typical endurance exercise and high intensity interval exercise (HIE).

\section{Methods}

\section{Subjects}

Subjects were nine active males (mean age: $27 \pm 12$ years, mean height: $169.6 \pm 4.4 \mathrm{~cm}$, mean weight: $71.9 \pm 16.6 \mathrm{~kg}, \mathrm{Vo}_{2} \max : 47.2 \pm$ $10.5 \mathrm{ml} / \mathrm{kg} . \mathrm{min}$ ) including 65 years old. All subjects were informed of the procedure and any risks, and gave written informed consent before participation. The study was approved by the Ethics committee of Fukuoka University.

\section{Exercise load settings}

We used cycle ergometers (Rehcor, Lode, Groningen, Netherlands) while subjects performed a graded ramp exercise test. After 15 min rest in a sitting position, the subjects warmed up for $4 \mathrm{~min}$ at 10 watts. During the test, 1 watt of load was added every 4 seconds until volitional fatigue. Gas analysis and electrocardiogram were measured during the test. Throughout the procedure, gas exchange was monitored continuously using the metabolic cart with mass spectrometry (ARCO2000, Arco System, Chiba, Japan). The measures of gas concentration and amount of ventilation were converted to values per minute and the oxygen uptake was calculated. At 3 and $5 \mathrm{~min}$ after the exercise, blood was collected from the earlobes and the concentration of lactate was measured.

From the changes in oxygen inhalation and carbon dioxide exhalation during exercise, anaerobic threshold (an indirect measure of the lactate threshold (LT), moderate intensity) was determined

Correspondence to: Hiroaki Tanaka, Fukuoka University Institute for Physical Activity, Fukuoka University, 8-19-1 Nanakuma Johnanku Fukuoka, Japan 8140180, E-mail: htanaka@fukuoka-u.ac.jp

Received: June 29, 2017; Accepted: July 22, 2017; Published: July 24, 2017 
using the V slope method. VO2 max intensity (maximal intensity) was determined from the regression equation of exercise load and oxygen uptake, and high intensity was calculated (between maximal and moderate intensities) as follows. high intensity $=$ (maximal Intensity + moderate Intensity) $\div 2$.

\section{Intermittent exercise test at determined intensity}

Subjects arrived at 07:00-08:30 and consumed a standardized breakfast [(energy: $476 \mathrm{kcal}$; carbohydrates: 57.1\%; fat: $28.7 \%$; protein: $14.1 \%)$. Approximately 1 hour later, they performed 20 sets of intermittent exercise using the power ergometer (Powermax-VIII, Combi Wellness, Tokyo). The experimental protocol was shown in Figure 2. The intensity of exercise was at three levels (Maximal, High and Moderate). Participants performed each protocol for one week, in a random order. One set at Maximal intensity lasted $60 \mathrm{~s}$, and the exercise time for the High and Moderate intensity exercise types was adjusted to obtain the same exercise volume. The resting time for the Maximal condition was $240 \mathrm{~s}$, and the resting time for High and Moderate conditions was calculated as follows: $300 \mathrm{~s}-$ [exercise time].

Needle muscle biopsy samples were taken during resting time from the vastus lateralis of one thigh under local anesthesia, as previously described [7], directly after exercise and $3 \mathrm{~h}$ after exercise. Muscle samples were collected from the vastus lateralis in the dominant foot. We collected samples of 5-10 mg at a time, and the same sampling method was used before and after exercise. Collected samples of skeletal muscle were promptly separated from blood using a sterilized gauze, frozen with liquid nitrogen and stored at $-80^{\circ} \mathrm{C}$ until the analysis.

The lactate concentration in the blood was measured before and after exercise. We asked subjects to estimate their rate of perceived exertion [RPE] after 5, 10, 15 and 20 sets of exercise.

\section{Muscle analysis}

Gene expression analysis: Total RNA was extracted from muscle sample [5mg] by the acid guanidine phenol chloroform [AGPC] method [ISOGEN, Nippon Gene Co Ltd, Toyama, Japan] with DNase treatment [Deixyribonucease I, Invitrogen Coorp., Carlsbad, CA, USA]. cDNA was synthesized from 1 ug of total RNA by reverse transcriptional reagents [Transcriptor First Stand cDNA synthesis kit, Roche Applied Science, Penzberg, Germany]. The PGC-1aand $\beta$ actin gene expressions levels were analyzed by real time RT-PCR [LightCycler and FastStart DNA MasterPLUS SYBR Greeen I, Roch apllied Science, Penzberg, Germany] and those gene expressions were quantified by the relative standard curve method. A prior analysis was carried out to determine the PCR conditions and the PCR period was stored as a calibrator sample.

The prior PGC product was extracted using a PCR product purifyication kit [High pure PCR procuct purifyication kit, Roche Applied Science, Penzberg, Germany] and the sample was stored at $-30^{\circ} \mathrm{C}$. Diluted calibrator samples were included in each analysis to make a standard curve. The PGC- $\alpha$ and PDK gene expression were normalized by $\beta$-actin. The intra and interassay coefficient variations were $12 \%$ and $15 \%$. The specifity of the PCR product was identified by a melting curve analysis, which determined the temperature of denatureation of the PCR product by hearting.

Protein quantification: Skeletal muscles was homogenized in icecold homogenization buffer [50 mM Tris [PH 7.5] $137 \mathrm{mM} \mathrm{NaCL}, 2.7$ $\mathrm{mM} \mathrm{KCL}, 1 \mathrm{mM} \mathrm{MgCl}_{2}$, $1 \%$ Triton X-100, 10\% [w/v] glycerol, $10 \mathrm{mM}$ $\mathrm{NaF}, 1 \mathrm{mM}$ EDTA, $5 \mathrm{mM}$ sodium pyrophosphate, $0,5 \mathrm{mM} \mathrm{Na}_{3} \mathrm{VO}_{4}$, lug ml ${ }^{-1}$ leuptin, $0.2 \mathrm{mM}$ phenylmethyl sulfonyl fluoride, $1 \mathrm{ug} \mathrm{ml}^{-1}$ aprotnin, $1 \mathrm{mMdithiothreitol,} 1 \mathrm{mM}$ benzamidine, $1 \mathrm{uM}$ microcystin] using Polytron homogenizer. Homoginates were rotated for $60 \mathrm{~min}$ at $4^{\circ} \mathrm{C}$ and centrifuged $\left[12,000 \mathrm{~g}\right.$ for $10 \mathrm{~min}$ at $\left.4^{\circ} \mathrm{C}\right]$, and the protein content of supernatant was determined using commercial kit assay [Bio-Rad, Richmond, CA, USA]. An aliquot of muscle homogenate [50ug protein] was mixed with Laemmli buffer.

The sample were separated and identified using SDS-PAGE and transferred to polyvinylidenedifluoride membranes. Non-specific binding was blocked in TBST [ $10 \mathrm{mM}$ Tris, $100 \mathrm{mM} \mathrm{NaCL}, 0.02 \%$ Tween 20] for $2 \mathrm{~h}$ at room temperature. Membranes were incubated overnight with primary anitbodies directed towards phosphoacetyl-CoA carboxylase [ACC] $\operatorname{Ser}^{79}$ [1:500; Cell Signaling no, 9221]. Membranes were washed in TBS-t and incubated with appropriate secondary antibody for $1 \mathrm{~h}$ at room temperature. Antibody binding was visualized by enhanced chemiluminescence [ECL; GE Healthcare, Arlington Heights, IL,USA] and quantified by densitometry [CS800 Calibrated Imaging Densitometer, Bio-Rad].

\section{Statistical analysis}

The data values in the study were expressed as means \pm SD. For all statistical processing IBM SPSS Statistic Ver 18 (SPSS Inc., Chicago, USA) was used. $\mathrm{P}<0.05$ was used as the threshold for statistical significance.

For the purposes of analysis, the amount of mRNA at rest was taken to have a value of 1 , and amplification was estimated for PGC-1 $\alpha$ and PDK. For positively skewed distributed variables, log-transformation was performed. A two-way repeated measures ANOVA method [time and exercise model] was used. When a significant main effect was observed, Bonferroni post hoc analysis was used to examine the difference.

Paired t-tests were used to compare within-group differences [baseline vs post]. Statistical significance was accepted at $\mathrm{P}<0.05$.

\section{Result}

Maximal intensity interval exercise (MIE) was set at $245 \pm 36$ watts corresponding to $100 \% \mathrm{VO} 2 \mathrm{max}$, High intensity interval exercise (HIE ) at $179 \pm 23$ watts corresponding to $74 \pm 3 \% \mathrm{VO} 2 \mathrm{max}$ and moderate intensity at anaerobic threshold interval eaercise (AIE ) at $113 \pm 14$ watts corresponding to $48 \pm 7 \% \mathrm{VO} 2 \mathrm{max}$ ). Exercise duration was $60 \mathrm{~s}$ for MIE, $82 \pm 4$ s for HIE, and $132 \pm 19$ s for AIE to the same amount of exercise and rest of the time for $5 \mathrm{~min}$ were stop exercise and repeated 20 times.

The results are shown in Figure 1. Three hours after the exercise, the volume of PGC-1 $\alpha$ mRNA increased significantly in all

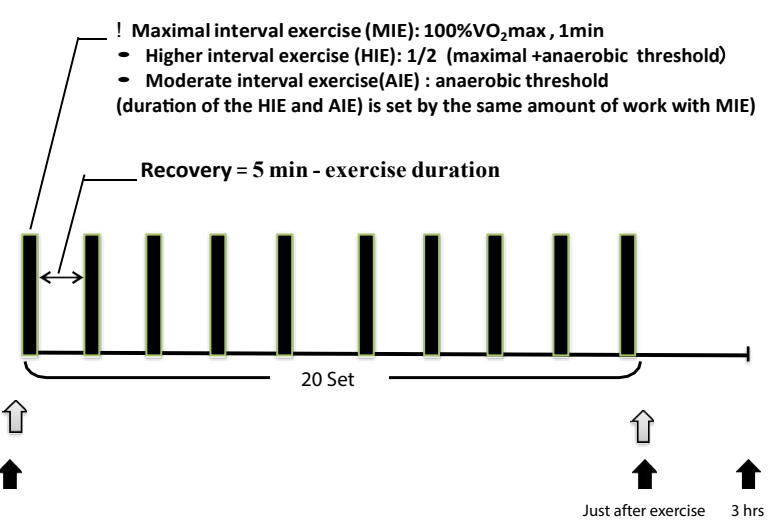

Figure 1. Experimental protocol. 

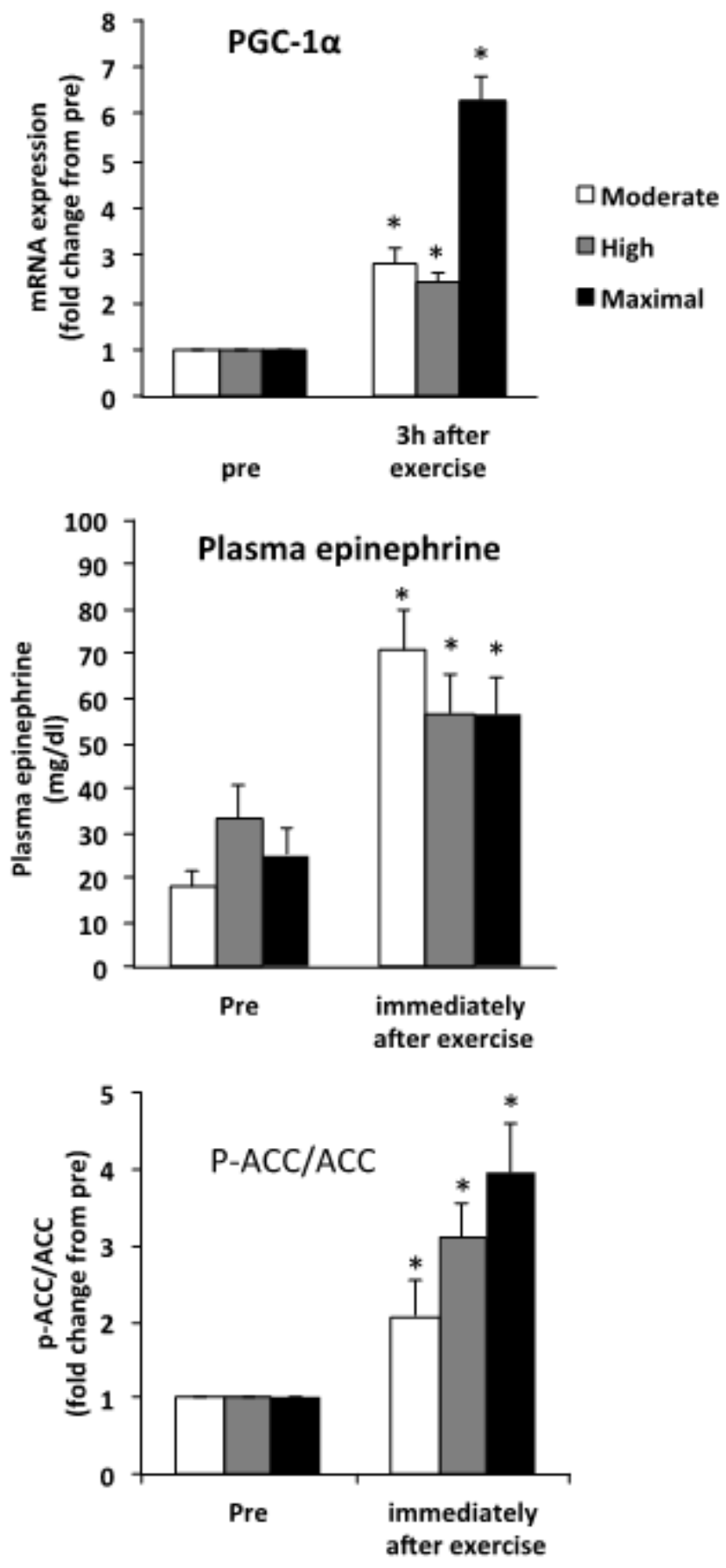

* Significant $(\mathrm{P}<0.05)$ main effects of time were found.

Figure 2. Summary data (mean $\pm \mathrm{SE}$ ) from the moderate, higher, and maximal conditions, showing the magnitude of the change in muscle PGC-1 $\alpha$ mRNA abundance, plasma epinephrine and muscle ACC-p level. Total RNA was isolated from muscle biopsies preexercise, , and $3 \mathrm{~h}$ post exercise plasma epinephrine and ACC-p/ACC from the biopsies immediately after exercise.

conditions 4.9 fold for MIE, 2.5 fold for HIE and 2.8 fold for AIE, but no significant difference in conditions. Plasma epinephrine levels increased significantly, and the increase was similar in all conditions. ACC increased significantly in all conditions 3.9 fold for MIE, 3.1 fold for HIE and 2.1 fold for AIE, but no significant difference in conditions.

\section{Discussion}

A number of studies have reported increased PGC-1 $\alpha$ mRNA expression as a result of endurance training for 40 to $90 \mathrm{~min}$ [3]. However, no previous studies have shown an increase in PGC-1a with easily performed moderate exercise interrupted by short breaks. The current study revealed an increase in PGC-1 $\alpha$ following moderate interval exercise similar to previous reports of increased PGC-1 $\alpha$ following HIE [9-11] and very MIE [12,13]. Gibala et al. [5] instructed subjects to cycle for four $30 \mathrm{sec}$ "all out" exercise bouts interspersed with 4 min rest periods. That study found a relative increase in PGC1a mRNA expression that was relatively smaller than the increase we observed in the current study following AIE [6].

Interestingly, even AIE training $\left(48 \pm 7 \% \mathrm{VO}_{2} \max \right)$ was observed to induce a similar increase in PGC-1 $\alpha$ mRNA compared with HIE (74 $\left.\pm 3 \% \mathrm{VO}_{2} \max \right)$. Previous studies have also reported an attenuated response in post-training exercise bouts at a similar absolute training intensity $[10,14]$. Discrepancies among previous studies may be related to the amount of exercise. The difference between the current study and the previous studies was in the duration: In previous studies it remained the same pre and post training, however in the current study it different (i.e. longer for lower intensity). $\beta_{2}$-adrnergic receptor activation is a potential mechanism underlying the PGC-1 $\alpha$ mRNA increase we observed. In mouse studies, even very slow treadmill running was found to induce a 2-fold increase in PGC-1 [15], which was inhibited by a $\beta_{2}$-AR antagonist [16]. It has been well established that plasma catecholamine levels are dependent on the intensity and duration of exercise $[17,18]$ We used moderate-intensity exercise at the anaerobic threshold, which is an indirect method for determining LT, because the intensity corresponded to the catecholamine threshold [19]. In a previous study, we found that the exercise below LT, which is below catecholamine threshold, could not induce an increase in PGC-1a even though the total amount was the same as exercise above LT [20]. As expected, we observed a significant increase in plasma epinephrine following moderate intensity interval exercise, similar to that induced by higher intensity interval exercise. This is likely because the duration of every bout of exercise was longer in the moderate intensity interval exercise, so the total amount of exercise was the same. AMPK also stimulates PGC-1 $\alpha$ expression. Despite the easily performed AIT, AMPK activity may be increased as ACC phosphorelation, sensitive indicator of skeletal muscle AMPK activity [21, 22], increased.

In conclusion, the present results provide evidence that even moderate intensity interval exercise, which can be easily performed by every body including cardiac patient and elderly people, is sufficient to activate the genes that contribute to endurance training adaptation such as mitocondrial biogenesis.

\section{Acknowledgments}

The work was funded by a JSPS Grant-in-Aid for Scientific Research [A] [25242065], and by a grant from Fukuoka University.

\section{References}

1. Lee IM, , Shiroma EJ, Lobelo F, Puska P, Blair SN, et al. (2012) Effect of physical inactivity on major non-communicable diseases worldwide: an analysis of burden of disease and life expectancy. Lancet [London, England] 380: 219-229. [Crossref]

2. Handschin C, Spiegelman BM (2008) The role of exercise and PGClalpha in inflammation and chronic disease. Nature 454: 463-469. [Crossref] 
3. Tanaka H, K. M, Shiose K (2012) An optimal exercise protocol for improving endurance performance and health. J Phys Fitness Sports Med 1: 595-604

4. Little JP, Safdar A, Bishop D, Tarnopolsky MA, Gibala MJ (2011) An acute bout of high-intensity interval training increases the nuclear abundance of PGC-1alpha and activates mitochondrial biogenesis in human skeletal muscle. Am J Physiol Regul Integr Comp Physiol 300: R1303-1310. [Crossref]

5. Gibala MJ, McGee SL, Garnham AP, Howlett KF, Snow RJ, et al. (2009) Brief intense interval exercise activates AMPK and p38 MAPK signaling and increases the expression of PGC-1alpha in human skeletal muscle. J Appl Physiol [1985] 106: 929934. [Crossref]

6. Hood MS, Little JP, Tarnopolsky MA, Myslik F, Gibala MJ (2011) Low-volume interval training improves muscle oxidative capacity in sedentary adults. Med Sci Sports Exerc 43: 1849-1856. [Crossref]

7. Nishida Y, Tanaka H, Tobina T, Murakami K, Shono N, et al. (2010) Regulation of muscle genes by moderate excersise. Int J Sports Med 31 (9): 656-670.

8. Tobina T, Nakashima H, Mori S, Abe M, Kumahara H, et al. (2009) The utilization of a biopsy needle to obtain small muscle tissue specimens to analyze the gene and protein expression. J Surg Res 154: 252-257. [Crossref]

9. Cluberton LJ, McGee SL, Murphy RM, Hargreaves M (2005) Effect of carbohydrate ingestion on exercise-induced alterations in metabolic gene expression. $J$ Appl Physiol 99: 1359-1363. [Crossref]

10. Nordsborg NB, Lundby C, Leick L, Pilegaard H (2010) Relative workload determines exercise-induced increases in PGC-1alpha mRNA. Med Sci Sports Exerc 42: 1477 1484. [Crossref]

11. Petersen AC, McKenna MJ, Medved I, Murphy KT, Brown MJ, et al. (2012) Infusion with the antioxidant $\mathrm{N}$-acetylcysteine attenuates early adaptive responses to exercise in human skeletal muscle. Acta Physiol [Oxf] 204: 382-392. [Crossref]

12. Coffey VG, Jemiolo B, Edge J, Garnham AP, Trappe SW, et al. (2009) Effect of consecutive repeated sprint and resistance exercise bouts on acute adaptive responses in human skeletal muscle. Am J Physiol Regul Integr Comp Physiol 297: R1441-1451. [Crossref]
13. Serpiello FR, McKenna MJ, Bishop DJ, Aughey RJ, Caldow MK, et al. (2012) Repeated sprints alter signaling related to mitochondrial biogenesis in humans. Med Sci Sports Exerc 44: 827-834. [Crossref]

14. Stepto NK, Benziane B, Wadley GD, Chibalin AV, Canny BJ, et al. (2012) Shortterm intensified cycle training alters acute and chronic responses of PGC1alpha and Cytochrome C oxidase IV to exercise in human skeletal muscle. PLoS One 7: e53080. [Crossref]

15. Tadaishi M, Miura S, Kai Y, Kawasaki E, Koshinaka K, et al. (2011) Effect of exercise intensity and AICAR on isoform-specific expressions of murine skeletal muscle PGC-1alpha mRNA: a role of beta[2]-adrenergic receptor activation. Am J Physio Endocrinol Metab 300: E341-349. [Crossref]

16. Miura S1, Kai Y, Kamei Y, Ezaki O (2008) Isoform-specific increases in murine skeletal muscle peroxisome proliferator-activated receptor-gamma coactivator1alpha (PGC-1alpha) mRNA in response to beta2-adrenergic receptor activation and exercise. Endocrinology 149: 4527-4533. [Crossref]

17. Cryer PE (1980) Physiology and pathophysiology of the human sympathoadrenal neuroendocrine system. $N$ Engl J Med 303: 436-444. [Crossref]

18. Perrault H, Cantin M, Thibault G, Brisson GR, Brisson G, et al. (1991) Plasma atriopeptin response to prolonged cycling in humans. J Appl Physiol [1985] 70: 979987. [Crossref]

19. Mazzeo RS, Marshall P (1989) Influence of plasma catecholamines on the lactate threshold during graded exercise. J Appl Physiol [1985] 67: 1319-1322. [Crossref]

20. Tobina T, Yoshioka K, Hirata A, Mori S, Kiyonaga A, et al. (2011) Peroxisomal proliferator-activated receptor gamma co-activator-1 alpha gene expression increases above the lactate threshold in human skeletal muscle. J Sports Med Phys Fitness 51: 683-688. [Crossref]

21. Chen ZP, Stephens TJ, Murthy S, Canny BJ, Hargreaves M, et al. (2003) Effect of exercise intensity on skeletal muscle AMPK signaling in humans. Diabetes 52: 22052212. [Crossref]

22. Park H, Kaushik VK, Constant S, Prentki M, Przybytkowski E, et al. (2002) Coordinate regulation of malonyl-CoA decarboxylase, sn-glycerol-3-phosphate acyltransferase, and acetyl-CoA carboxylase by AMP-activated protein kinase in rat tissues in response to exercise. J Biol Chem 277: 32571-32577. [Crossref]

Copyright: (C2017 Tanaka H. This is an open-access article distributed under the terms of the Creative Commons Attribution License, which permits unrestricted use, distribution, and reproduction in any medium, provided the original author and source are credited. 